\title{
Solid-Duty-Control Technique for Alleviating the Right-Half-Plane Zero Effect in Continuous Conduction Mode Boost Converters
}

\author{
Han-Hsiang Huang, Chi-Lin Chen, Dian-Rung Wu, and Ke-Horng Chen, Senior Member, IEEE
}

\begin{abstract}
This paper proposes a solid-duty-control (SDC) technique for application in boost converters to maintain a constant duty value and reduce dip voltage during load transient periods. Fast transient response was also achieved because of the variable transient enhancement controller. The proposed SDC technique can provide a stable and regulated output for edge-lit light-emitting diode backlight systems. This converter was used in a $0.25-\mu \mathrm{m}$ CMOS process. Experimental results show that compared with a conventional design without a fast transient technique, the proposed approach yields about $30 \%$ and $80 \%$ improvement in undershoot voltage and recovery time, respectively, as load current changes from 50 to $250 \mathrm{~mA}$.
\end{abstract}

Index Terms-Adaptive off-time., alleviating skill, boost converter, dc-dc converter, light-emitting diode (LED), right-halfplane (RHP), solid duty control, valley current control.

\section{INTRODUCTION}

$\mathbf{T}$ HE CURRENT trend in the development of current liquid crystal display (LCD) panels is geared toward weightlessness and thinness. In this regard, edge-lit light-emitting diode (LED) backlight configuration has become a popular technique applied to medium- and small-size LCDs [1]-[3]. Fig. 1(a) illustrates a conventional block diagram of an LCD TV with edge-lit LED backlight units containing three LED colors. To obtain perfect image quality, light guides in the edge-lit LED backlight are designed to prevent total internal reflection and uniformly distribute light emitted from the LED sources across the light-guide surface [4]-[7]. Furthermore, the LED backlight driver, which is composed of boost converters, must be able to handle the requirements of fast transience, high stability, power efficiency, and space minimization to handle large instant load variations without sacrificing image quality and increasing motion blur effects [8]-[10]. The conventional current-mode boost converter contains one dominant pole and two zeros, the righthalf-plane (RHP) and left-half-plane (LHP) zero. However, the RHP zero results in a tradeoff between fast transient response

Manuscript received February 9, 2011; revised April 11, 2011; accepted May 12, 2011. Date of current version December 16, 2011. This work was supported by the National Science Council, Taiwan under Grant NSC 97-2221-E-009-172 and Grant NSC 97-2220-E-009-027. Recommended for publication by Associate Editor C. K. Tse.

The authors are with the Department of Electrical and Control Engineering, National Chiao Tung University, Hsinchu 300, Taiwan (e-mail: hhhuang. eic95g@nctu.edu.tw; zell1412@yahoo.com.tw; iamthebestpop_e@yahoo. com.tw; khchen@cn.nctu.edu.tw).

Color versions of one or more of the figures in this paper are available online at http://ieeexplore.ieee.org.

Digital Object Identifier 10.1109/TPEL.2011.2157835

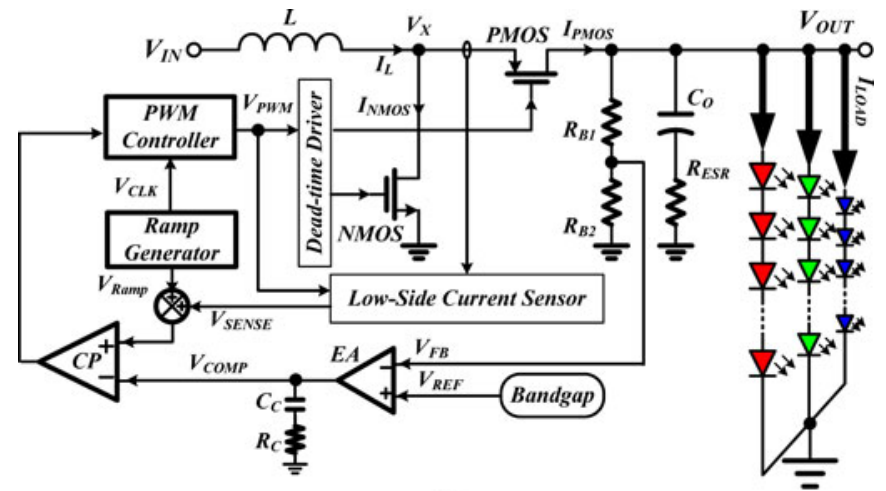

(a)

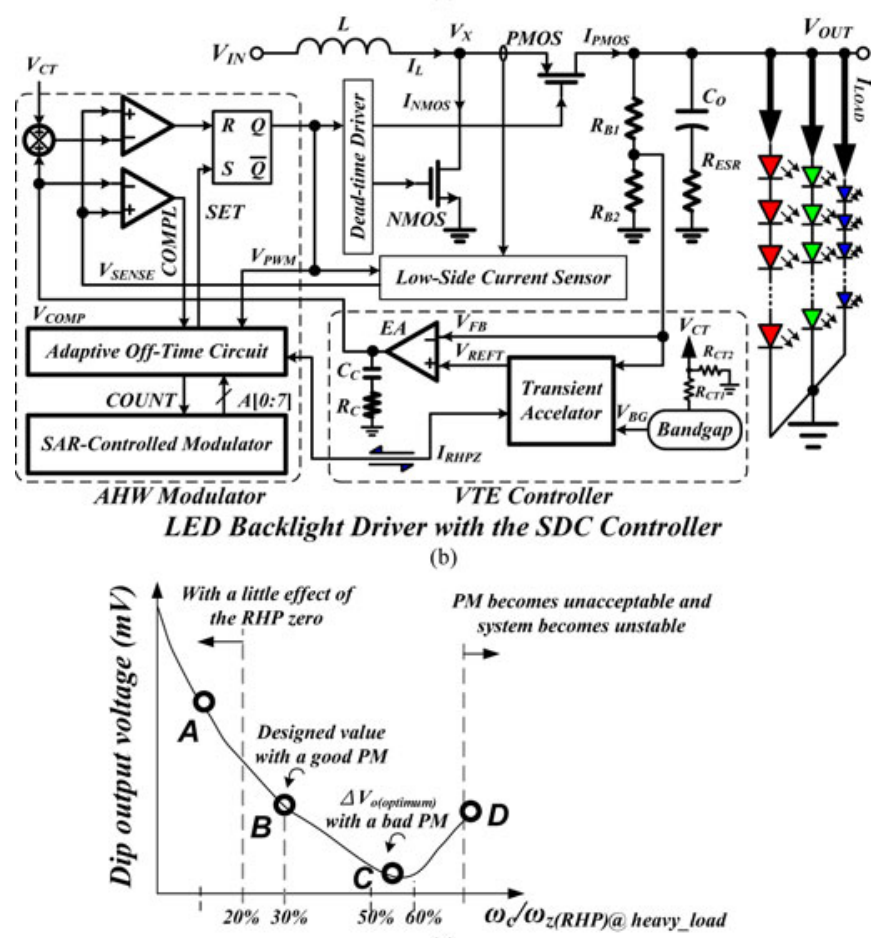

(c)

Fig. 1. (a) Conventional current-mode boost converter. (b) Proposed boost converter with SDC controller containing the AHW and VTE controllers. (c) Selection of the RHP zero can simultaneously ensure transient response and system stability.

and system stability in the boost converters, which operate in (CCM) [11], [12].

A number of previous studies have mentioned the existence of the RHP zero that limits the system bandwidth because of system stability considerations [13]-[16]. In conventional design, the 
relationship between the crossover frequency and the RHP zero enables the tradeoff between transient response and the system stability [see Fig. 1(c)]. The crossover frequency is generally designed to be smaller than $10-20 \%$ of the $\omega_{\mathrm{RHPZ}}$ at heavy loads. Point A shown in Fig. 1(c) is slightly influenced by the RHP zero on the phase margin, but the transient response time considerably slows down. As a result, the output voltage of the system has a large dip voltage when load current variations occur because of the limited system bandwidth. If the crossover frequency is designed as point B in Fig. 1(c), the RHP zero imposes a serious effect on the drop of the output voltage when load transient occurs. However, the higher crossover frequency can ensure that the dip voltage is smaller than that at point A. The designed value is usually located at point $\mathrm{B}$.

Conversely, the discontinuous conduction mode in conventional boost converter design is widely used in obtaining simple compensation because the RHP zero appears at high frequencies [17], [18]. However, the slow response cannot satisfy the requirements of LED backlight systems.

This paper presents a solid-duty-control (SDC) technique for application in a boost converter with CCM operation [see Fig. 1(b)] to alleviate the effects of the RHP zero and improve transient response time. As a result, high bandwidth and fast transient response can be achieved simultaneously. The rest of the paper is arranged as follows. The methodology of SDC control is introduced in Section II. Section III presents the operation of the proposed SDC boost converter. The implementation of the proposed variable transient enhancement (VTE) circuit and adaptive hysteresis window (AHW) modulator is illustrated in Section IV. Experimental results shown in Section V demonstrate the advantages of the SDC control technique. Finally, the conclusions drawn are presented in Section VI.

\section{Design of The SDC TeChNiQue}

The duty ratio that changes during the load transient period results in a larger output voltage drop because the RHP zero moves toward the origin. Therefore, the SDC method is proposed to decrease the output voltage drop by keeping the duty ratio constant. That is, the SDC method can reduce the RHP effect because of the extension of the on-time and off-time periods during the load transient period.

\section{A. Analysis in the Time Domain}

As illustrated in Fig. 2(a), the voltage variation on the output capacitor during the on-time and off-time periods can be expressed as (1) and (2), respectively [19]. Fig. 2(b) shows the timing diagrams of the voltage and currents related to Fig. 2(a):

$$
\begin{aligned}
V_{C_{O} \text { _ontime }} & =\frac{I_{\mathrm{Load}}}{C_{O}} D T_{S} \\
V_{C_{O} \text { _offtime }} & =\frac{\left(I_{L}-I_{\mathrm{Load}}\right)}{C_{O}} D^{\prime} T_{S} .
\end{aligned}
$$

Here, $I_{L}$ is the inductor average current during the off-time period. Therefore, the total voltage drop on in the output ca-
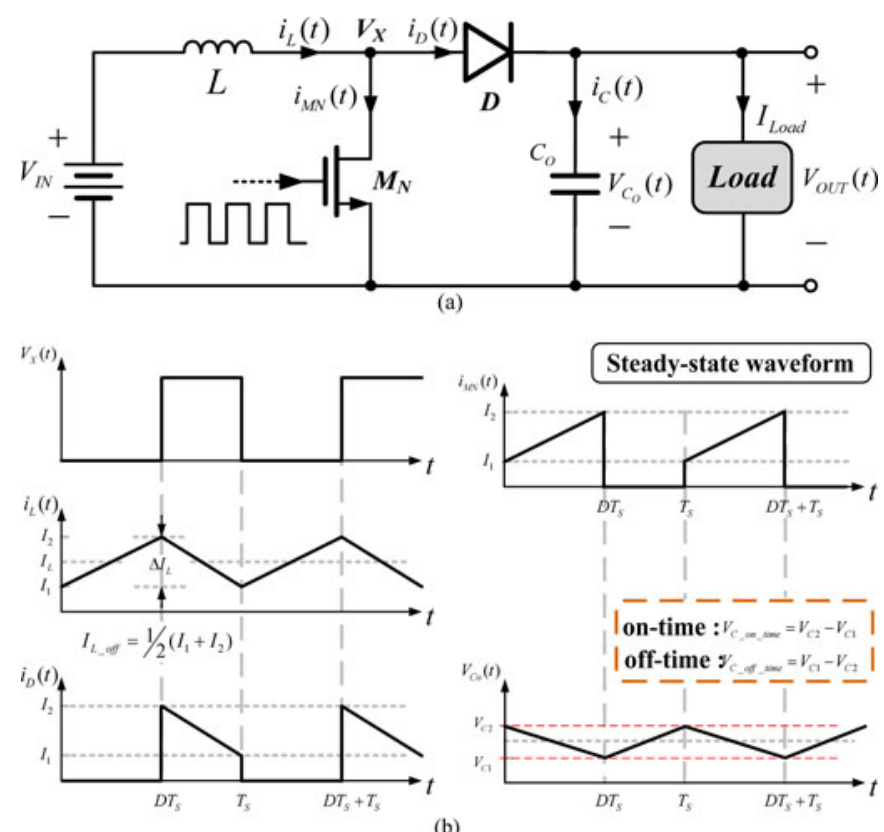

(b)

Fig. 2. (a) Boost converter scheme. (b) Timing diagram of some important waveforms.

pacitor $C_{O}$ during one switching period $T_{S}$ can be expressed as

$$
\begin{aligned}
\Delta V_{C_{O}} & =-V_{\mathrm{drop}}=V_{C_{O} \text { _offtime }}-V_{C_{O} \text { _ontime }} \\
& =\frac{T_{S}}{C_{O}}\left(D^{\prime} I_{L}-I_{\mathrm{Load}}\right) .
\end{aligned}
$$

The proposed SDC method extends the on-time and off-time periods by the same ratio during transient response to ensure that the duty ratio is kept constant (see Fig. 3). Assume that the switching period is changed from $T_{s}$ to $m T_{\mathrm{sI}}$, where " $m$ " is the extended time ratio for on-time and off-time values for simplicity. The voltage drop on the output capacitor can then be expressed as

$$
\begin{aligned}
\Delta V_{C_{O} \_\operatorname{tran}_{n}} & =-\Delta V_{\text {drop_SDC }_{n}} \\
& =\frac{T_{S_{n}}}{C_{O}} \cdot\left[I_{L_{-} \text {offtime }_{n}} D_{n}^{\prime}-I_{\text {Load }_{n}}\right]
\end{aligned}
$$

where

$$
\begin{aligned}
I_{L_{-} \text {offtime }_{n}}= & \frac{1}{2}\left(I_{2}+I_{3}\right)=I_{L}-\frac{\Delta I_{L}}{2}+\frac{1}{2} \frac{V_{\mathrm{IN}} D_{n} T_{S_{n}}}{L} \\
& +\frac{\Delta V_{\text {out }_{n}}}{L} D_{n}^{\prime} T_{S_{n}}
\end{aligned}
$$

and

$$
\Delta V_{\text {out }_{n}}=\frac{I_{L} D_{n-1}^{\prime}}{C_{O}}\left[D_{n} k T_{S_{n}}-D_{n-1} T_{S_{n-1}}\right]
$$

Hence, the voltage drop on the output capacitor $C_{O}$ with the SDC method can be rewritten as (5), where $k$ is the change ratio 


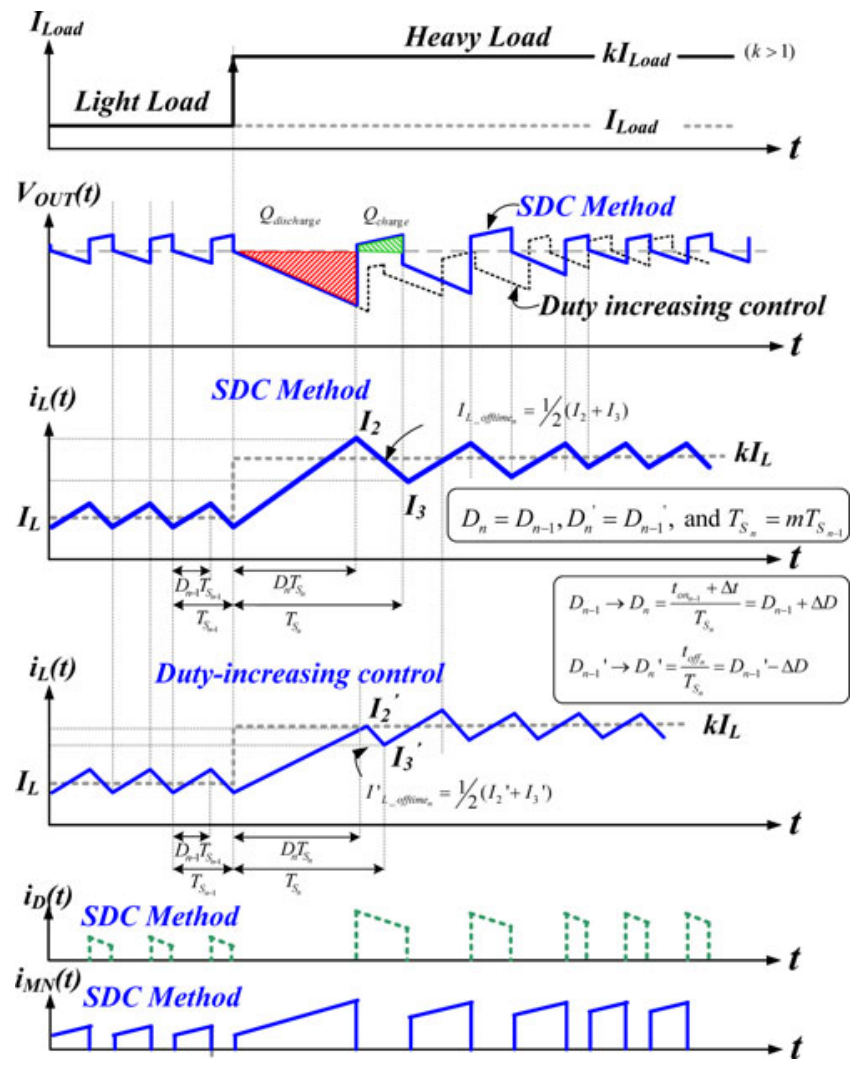

Fig. 3. Waveforms of inductor current, diode current, power MOSFET current, and output voltage in the SDC control method and inductor current of the dutyratio increasing control.

of the load current.

$$
\begin{aligned}
\Delta V_{C_{O} \_\operatorname{tran}_{n}}= & -\Delta V_{\mathrm{drop}_{2} \mathrm{SDC}_{n}}=\frac{m T_{S_{n-1}} D_{n-1}^{\prime}}{C_{O}} \\
& \times\left[\frac{V_{I N} D_{n-1} T_{S_{n-1}}}{2 L}(m-1)-I_{L}(k-1)\right. \\
& \left.+\frac{m I_{L} D_{n-1}\left(D_{n-1}^{\prime} T_{S_{n-1}}\right)^{2}}{2 L C_{O}}(m k-1)\right] .
\end{aligned}
$$

Compared with the control with an increasing duty ratio from $D$ to $D+\Delta D$ in the transient period, the switching period simultaneously increases and results in the voltage drop that can be expressed as

$$
\begin{aligned}
\Delta V_{C_{O} \text { tran }_{n}}= & -\Delta V_{\text {drop_D }} \text {-increasing } \\
& =\frac{T_{S_{n}}}{C_{O}} \\
& \times\left[I_{L_{-} \text {offtime }_{n}}^{\prime} D_{n}^{\prime}-I_{\text {Load }_{n}}\right]
\end{aligned}
$$

where

$$
\begin{aligned}
I_{L_{-} \text {offtime }_{n}}^{\prime}= & I_{L}+\frac{V_{\mathrm{IN}}}{2 L} \cdot\left[D_{n} T_{S_{n}}-D_{n-1} T_{S_{n-1}}\right] \\
& +\frac{\Delta V_{\text {out }_{n}} D_{n}^{\prime} T_{S_{n}}}{2 L} \\
\Delta V_{\text {out }_{n}}= & \frac{I_{L} D_{n-1}^{\prime}}{C} \cdot\left[D_{n} k T_{S_{n}}-D_{n-1} T_{S_{n-1}}\right] .
\end{aligned}
$$

Thus, the voltage drop across the output capacitor $C_{O}$ with the duty-ratio increasing control can be rewritten as

$$
\begin{aligned}
\Delta V_{C_{O} \_\operatorname{tran}_{n}}= & -\Delta V_{\mathrm{drop} \_} D \text {-increasing } \\
= & \frac{m T_{S_{n-1}}}{C_{O}}\left\{\frac{V_{I N} T_{S_{n-1}}}{2 L}\left[D_{n-1}(m-1)+m \Delta D\right]\right. \\
& \cdot\left(D_{n-1}^{\prime}-\Delta D\right)+I_{L}\left[(1-k) D_{n-1}^{\prime}-\Delta D\right] \\
& +\frac{\left(D_{n-1}^{\prime}-\Delta D\right) m T_{S_{n-1}}}{2 L} \cdot \frac{I_{L} D_{n-1}^{\prime} T_{S_{n-1}}}{C_{O}} \\
& \left.\times\left[k m\left(D_{n-1}^{\prime}+\Delta D\right)-D_{n-1}\right]\right\} .
\end{aligned}
$$

To identify a range of " $m$ " so that the voltage drop value in the SDC method is less than that in the duty-ratio increasing control in transient period. That is, the difference between (5) and (7) must be larger than or equal to zero. Therefore

$$
\Delta V_{\text {drop_D-increasing }}-\Delta V_{\text {drop_SDC }} \geq 0 .
$$

Substituting (5) and (7) into (8), the lower bound of the extension ratio of the on-time or off-time period can be derived as

$$
m \geq \frac{D_{n-1}-\left(2 L I_{L} / V_{\mathrm{IN}} T_{S_{n-1}}\right)}{2 D_{n-1}+\Delta D-1} .
$$

To minimize the settling time in the SDC method, the charge on the output capacitor during the on-time period is equal to the off-time period in case of transient period $\left(Q_{\text {discharge }}=\right.$ $Q_{\text {charge }}$ ). Hence, (5) must be set to zero. The upper bound of " $m$ " can be derived as

$$
m \leq 1+\frac{2 I_{L} L(k-1)}{V_{\mathrm{IN}} D_{n-1} T_{S_{n-1}}} .
$$

Finally, the summary of the range for " $m$ " can be expressed as

$$
\frac{D_{n-1}-\left(2 L I_{L} / V_{\mathrm{IN}} T_{S_{n-1}}\right)}{2 D_{n-1}+\Delta D-1} \leq m \leq 1+\frac{2 I_{L} L(k-1)}{V_{\mathrm{IN}} D_{n-1} T_{S_{n-1}}} .
$$

Therefore, the following implementation is based on the design value to satisfy the requirements defined by (11). Moreover, assume that factor " $m$ " is at least larger than one, and that the design value of the switching frequency must be at least larger than the expression shown in

$$
F_{S_{n-1}} \geq \frac{V_{\mathrm{IN}} \cdot\left[1-\left(D_{n-1}+\Delta D\right)\right]}{2 L I_{L}} .
$$

\section{B. Analysis in the Frequency Domain}

The small-signal model of the conventional current-mode boost converter is illustrated in Fig. 4 and the control-to-output transfer function is shown in (13) [19]. $R$ is the output resistance, $R_{f}$ denotes the current sensing gain, and $R_{\mathrm{ESR}}$ represents the 


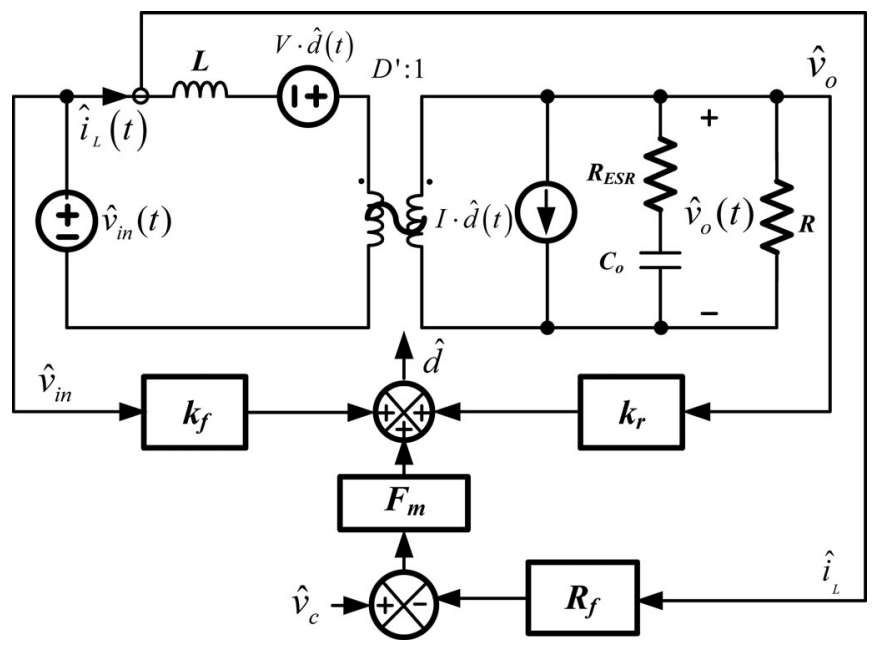

Fig. 4. Small-signal model of the conventional current-mode boost converter.

equivalent series resistance of output capacitor $C_{O}$ :

$$
\begin{aligned}
G_{v c} & =\frac{\hat{v}_{o}}{\hat{v}_{c}}=\frac{1}{R_{f}} \frac{G_{v d}}{G_{i d}} \\
& =G_{v c 0} \frac{\left(1-\left(s / \omega_{z(\mathrm{RHP})}\right)\right)\left(1+\left(s / \omega_{z(\mathrm{ESR})}\right)\right)}{\left(1+\left(s / \omega_{p 1}\right)\right)}
\end{aligned}
$$

where

$$
\begin{aligned}
G_{v d} & =\left.\frac{\hat{v}_{o}}{\hat{d}}\right|_{\hat{v}_{\mathrm{in}}=0}=\frac{V_{o}}{D^{\prime}} \cdot \frac{\left(1-s\left(L / D^{\prime 2} R\right)\right)\left(1+s R_{\mathrm{ESR}} C_{o}\right)}{1+s\left(L / R D^{\prime 2}\right)+s^{2}\left(L C_{o} / D^{\prime 2}\right)} \\
G_{i d} & =\left.\frac{\hat{i}_{L}}{\hat{d}}\right|_{\hat{v}_{i n}=0}=\frac{2 \cdot V_{o}}{D^{\prime 2} R} \cdot \frac{\left(1+s\left(R C_{o} / 2\right)\right)}{1+s\left(L / R D^{\prime 2}\right)+s^{2}\left(L C_{o} / D^{\prime 2}\right)} \\
G_{v c 0} & =\frac{D^{\prime} R}{2 R_{f}}, \quad \omega_{p 1}=\frac{2}{R C_{o}}, \quad \omega_{z(\mathrm{RHP})}=\frac{D^{\prime 2} R}{L} \\
\text { and } \quad \omega_{z(\mathrm{ESR})} & =\frac{1}{R_{\mathrm{ESR}} C_{o}} .
\end{aligned}
$$

The control-to-output transfer function contains one dominant pole $\omega_{p 1}$ and two zeros, which include one RHP zero $\omega_{z}(R H P)$ and one LHP zero $\omega_{z}(E S R)$. Moreover, the decrease in the value $D^{\prime}$ caused by the load transient response pushes the RHP zero toward the origin. This push results in a large dip voltage, which is the reason for keeping the duty ratio constant to cancel the effects of the RHP zero. Thus, the SDC method can improve the performance of the boost converter compared with the conventional design.

The proportional-integral (PI) compensation with a transfer function as shown in (15) is typically used to compensate for the system, with $G_{c 0}$ being the low-frequency gain of the PI compensator [20], [21]. Compensation zero $\omega_{z c 1}$ is used to cancel the effect of $\omega_{p 1}$, while compensation pole $\omega_{p c 1}$ forms the new dominant pole to determine the system bandwidth. The role of $\omega_{p c 2}$ is used to decrease the high-frequency gain affected by the existence of $\omega_{z \text { (RHP) }}$. Through the constant duty ratio and high-frequency compensation pole, the effect of the RHP zero can be effectively canceled:

$$
G_{c}=G_{c 0} \frac{\left(1+\left(s / \omega_{z c 1}\right)\right)}{\left(1+\left(s / \omega_{p c 1}\right)\right)\left(1+\left(s / \omega_{p c 2}\right)\right)} .
$$

\section{PRoposed SDC CONTROLleR}

To cancel the RHP zero effect and achieve faster transient response for reliable system stability, the proposed boost converter utilizes the SDC technique, which contains an AHW modulator and a VTE controller [see Fig. 1(b)].

The hysteresis window is formed by the value of $V_{\mathrm{CT}}$, which is generated by the voltage divider from the bandgap circuit and limits the output ripple within the hysteresis window [22]. Under heavy load conditions, the on-time period suddenly increases, whereas the off-time period decreases. The energy delivered to the output decreases in the beginning, causing the output to undergo a considerably large voltage drop. After the inductor current increases to a higher value, the output voltage can be restored to its regulated value. In other words, the RHP zero effect induces a large dip in the voltage and long transient response. Thus, the SDC controller includes the VTE controller to decrease the drop voltage and transient response time.

As shown in Fig. 5(a), the increasing on-time results in the off-time and the energy delivered to the output initially decreases in the conventional design when load current changes from light to heavy. Output voltage $V_{\mathrm{OUT}}$ (conv.) exhibits a large voltage drop because the RHP zero causes the output to initially lean toward the wrong direction during the transient period. The AHW modulator keeps the duty ratio constant during the load transient period because the increasing on-time accompanies the increasing off-time. Therefore, output voltage $V_{\text {OUT (proposed) }}$ exhibits a smaller dip voltage compared with those in conventional designs. That is, the AHW technique reduces the RHP zero effect. However, the transient response time does not change because of the identical bandwidths. The proposed VTE controller instantly increases the slope of the hysteresis window to further increase the speed of the transient response. As depicted in Fig. 5(b), the inductor current can be raised to the rated value to reduce transient response time.

\section{CiRCUIT IMPLEMENTATION}

In the proposed SDC controller, the basic submodules contain the AHW modulator and VTE controller to keep a nearly constant duty ratio and a fast transient response, respectively.

\section{A. AHW Modulator}

Fig. 6(a) illustrates the AHW modulator. According to the successive approximation register conversion, the adaptive offtime is controlled by capacitor array $C_{\text {off }}$ to decide off-time $t_{\text {off }}$ [23]. The controller bits [see Fig. 6(b)] can decide a suitable value for the charging capacitor to determine value $t_{\mathrm{off}}$. In the steady state, $t_{\text {off }}$ is kept constant. In the design of a conventional boost converter, once the load current changes, the value of $t_{\text {off }}$ decreases because of the effect of the RHP zero. As a result, a large voltage drop occurs because the output obtains less energy 


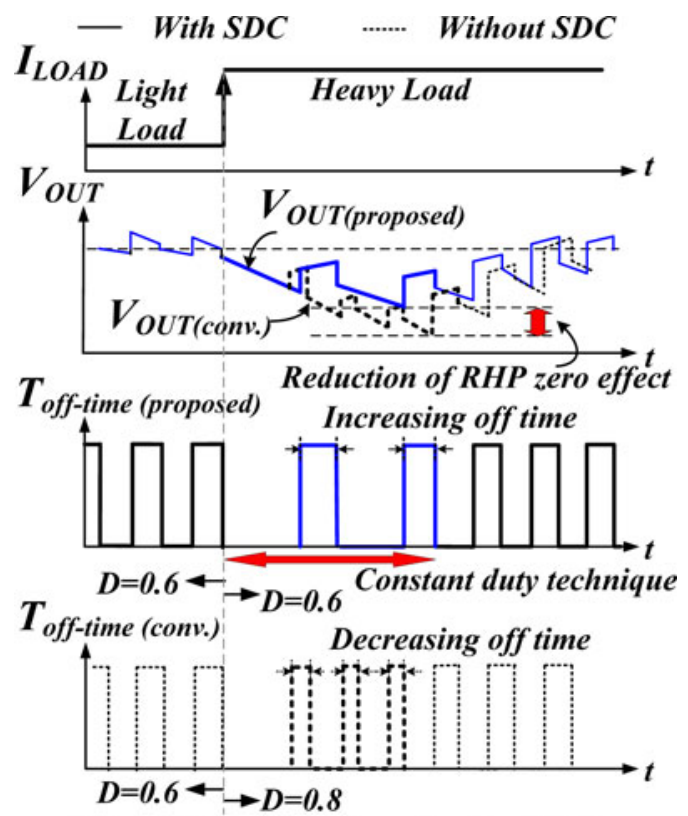

The AHW technique in the SDC

(a)

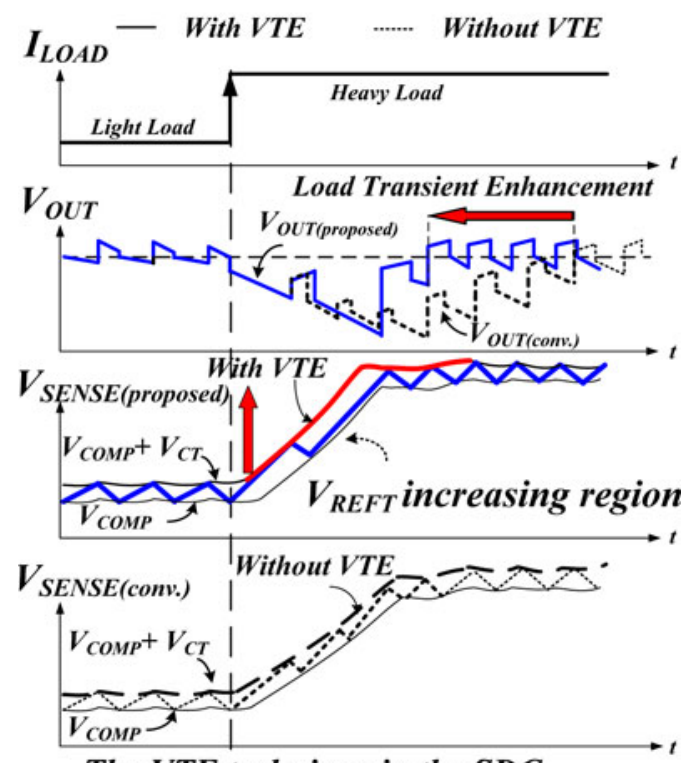

The VTE technique in the SDC

(b)

Fig. 5. Reduction in voltage drop and transient response are achieved using the AHW modulator and VTE controller, respectively.

from the input voltage source towing to the decrease in the off-time period.

Therefore, the AHW modulator prolongs $t_{\mathrm{off}}$ through decreasing charging current " $I_{\mathrm{CONST}}-I_{\mathrm{RHPZ}}$," and increases $V_{R}$ because of the injection of $I_{\mathrm{RHPZ}} \cdot t_{\mathrm{off}}$ is controlled by RHP zero control current $I_{\mathrm{RHPZ}}$ that stems from the VTE controller [see Fig. 7(a)]. As a result, the AHW modulator can ensure that the duty ratio cycle is kept constant even during the load transient period. The RHP zero effect can be effectively alleviated to guarantee low dip voltage during the load transient period. Furthermore, the duty ratio is kept nearly constant using the

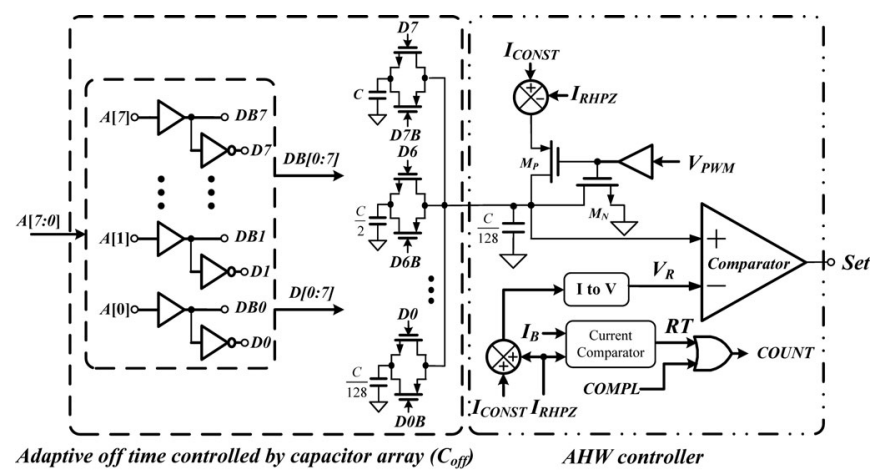

(a)

\begin{tabular}{|c|c|c|c|c|c|c|c|}
\hline & & & & & & & $\angle S B$ \\
\hline$A_{7}$ & $A_{6}$ & $A_{5}$ & $A_{4}$ & $A_{3}$ & $A_{2}$ & $A_{1}$ & $A_{0}$ \\
\hline C & $C$ & $\underline{C}$ & $\underline{C}$ & $C$ & $C$ & $C$ & $C$ \\
\hline & $\overline{2}$ & $\overline{4}$ & $\overline{8}$ & $\overline{16}$ & $\overline{32}$ & $\overline{64}$ & $\overline{128}$ \\
\hline
\end{tabular}

Fig. 6. (a) Schematic of the AHW modulator with adaptive off-time controller. (b) Controlling bits for determining the value of the charging capacitor.

AHW modulator. However, the switching frequency decreases, causing a slow transient response time. Thus, accelerating the transient response using the VTE controller is necessary for enhancing the performance of the SDC controller.

\section{B. VTE Controller}

To implement the RHP zero control current, the VTE controller is proposed to keep the duty ratio constant during the load transient period. Here, the $G_{m}$ amplifier [see Fig. 7(b)] converts the voltage difference between $V_{\mathrm{REF}}$ and $V_{\mathrm{FB}}$ to three current signals, $I_{\mathrm{OUT} 1}, I_{\mathrm{OUT} 2}$, and $I_{\mathrm{RHPZ}}[21]$, [24]. $I_{\mathrm{OUT} 1}$ flows through resistor $R_{1}$ to form two threshold voltages, $V_{H}$ and $V_{L}$. Current signal $I_{\mathrm{OUT} 2}$ is compared with a predefined constant current $I_{B}$ to decide the starting time of the transient period. During the transient period, reference voltage $V_{\mathrm{REF}}$ changes from $V_{L}$, which is designed equal to $V_{\mathrm{BG}}$ here, to $V_{H}$. This change causes the reference voltage (which is connected to the noninverting terminal of the error amplifier) to increase, thereby effectively enhancing the performance of the transient response. This is particularly true for the high-speed current comparator, which is accelerated because of the shunt-shunt feedback resistor formed by transistor $M_{N 4}$. In turn, this allows transistor $M_{N 4}$ to rapidly decide on the beginning condition of the transient response and further alleviate the effect of the RHP zero. Fig. 7(c) shows the waveforms with and without the VTE controller. The figure shows that the transient performance of the load transient response can be effectively improved.

\section{EXPERIMENTAL RESULTS}

The proposed SDC controller for edge-lit LED backlight systems was fabricated via the TSMC $0.25 \mu \mathrm{m} \mathrm{BCD}$ process. Fig. 8 shows the chip micrograph with a silicon area of $2.16 \mathrm{~mm}^{2}$. The LED driver provides a $12-\mathrm{V}$ regulated output voltage with a maximum loading current of $250 \mathrm{~mA}$. 


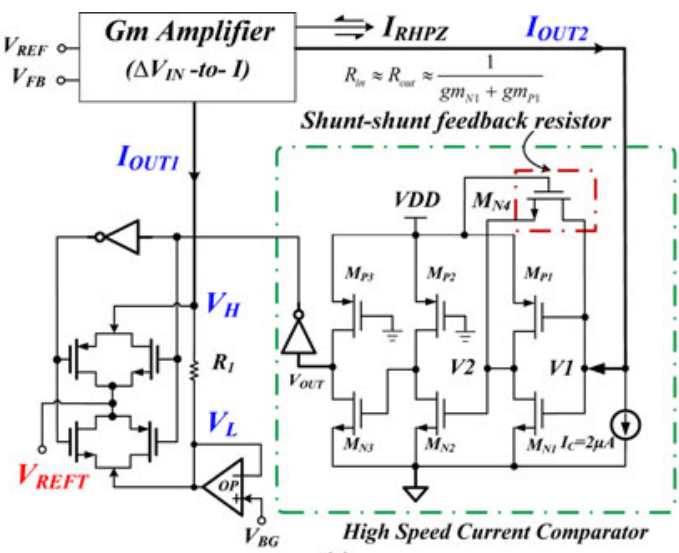

(a)

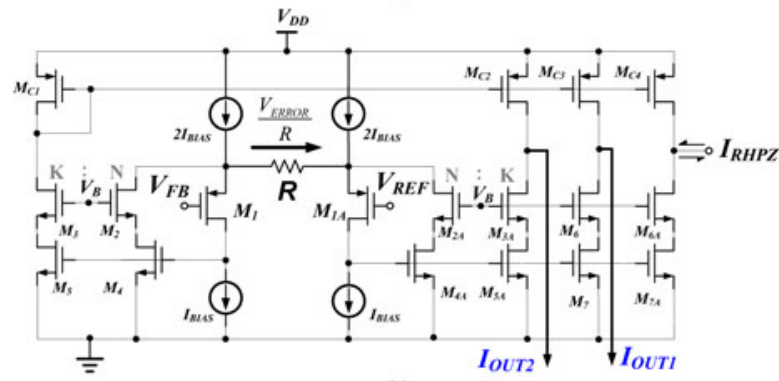

(b)

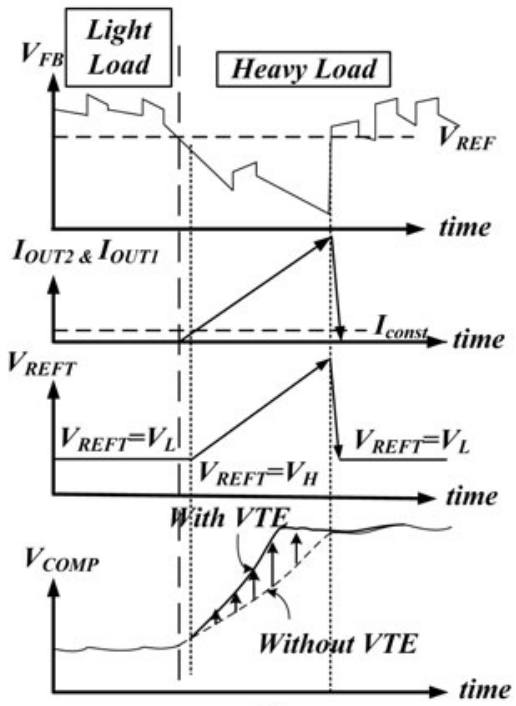

(c)

Fig. 7. (a) Structure of the VTE controller. (b) Schematic of the $G_{m}$ amplifier. (c) Improved performance during load transient response caused by the VTE controller.

To realize effect " $m$ " in decreasing the $V_{\text {OUT }}$ drop, the boost converter is tested with $V_{\text {IN }}=4 \mathrm{~V}, V_{\text {OUT }}=12 \mathrm{~V}$; thus, $D$ is $2 / 3$. Inductor $L$ is $6.8 \mu \mathrm{H}$ and output capacitor $C_{O}$ is $6.8 \mu \mathrm{F}$. The operation switching frequency is $1.4 \mathrm{MHz}$. Here, the load current changes from 50 to $250 \mathrm{~mA}$ and vice versa. That is, the value of $k$ is 5 . According to the derived equations, the range of factor " $m$ " ranges from 1 to 5.29. The simulation and calculation results during the first period are shown in Fig. 9. The larger the ratio factor " $m$ " chosen, the lesser is the switching frequency occurring during the load transient period. A reasonable limitation on crossover frequency $\omega_{c}$ should be below $1 / 10$ of the switch-

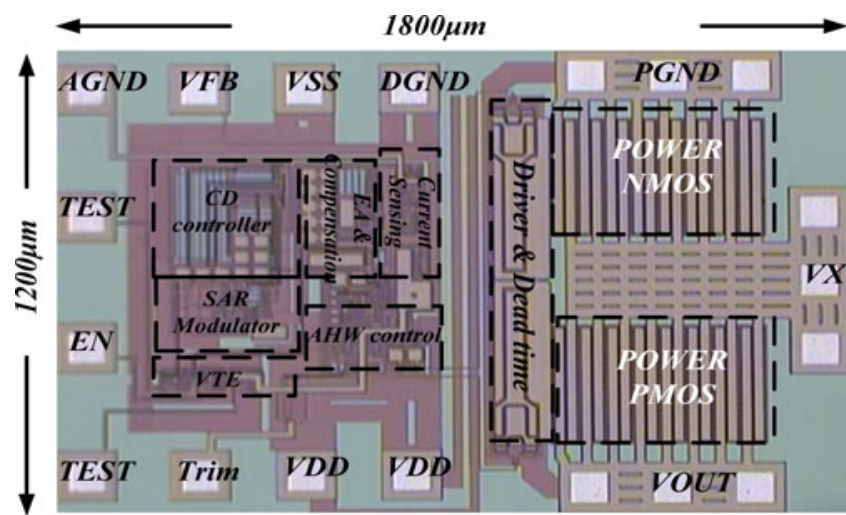

Fig. 8. Chip micrograph.

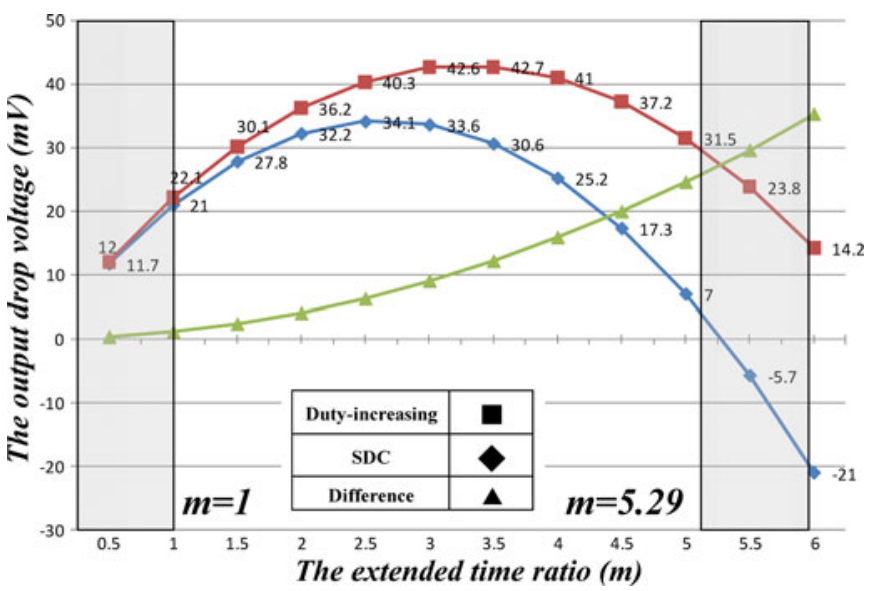

Fig. 9. Simulation and calculation results during the first load transient period.

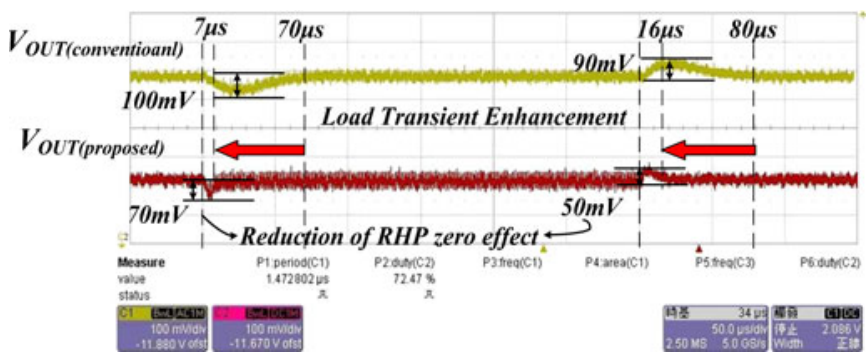

Fig. 10. Load transient response under a 200-mA load current variation in the conventional and proposed techniques.

ing frequency to reduce the switching output ripples. Thus, the value of " $m$ " cannot be increased to a large value because this can impose a serious effect on system stability. On the other hand, as the switching frequency decreases, more issues related to switching noise arise. In other words, the value of " $m$ " should be decreased to enhance system stability.

Fig. 10 shows the experimental results that include the output voltage of the proposed technique compared with the conventional pulsewidth modulation boost converter when load changes from 50 to $250 \mathrm{~mA}$ and vice versa. The undershoot voltages of the conventional and proposed techniques are 100 and $70 \mathrm{mV}$, respectively. The overshoot voltages of the conventional and proposed techniques are 90 and $50 \mathrm{mV}$, 
TABLE I

SUMMARY OF COMPARISON

\begin{tabular}{|c|c|c|c|c|c|c|}
\hline & Ref. [10] & Ref. [24] & Ref. [25]* & Ref. [26] & Ref. [27] & This Work \\
\hline Input voltage & $8-13.5 \mathrm{~V}$ & $3.05-5.5 \mathrm{~V}$ & $5 \mathrm{~V}$ & $0.8-2.4 \mathrm{~V}$ & $0.9-1.2 \mathrm{~V}$ & $2.7-4.3 \mathrm{~V}$ \\
\hline Output voltage & $16-30 \mathrm{~V}$ & $5.6-25 \mathrm{~V}$ & $1.5 \mathrm{~V}$ & $1.8-3.3 \mathrm{~V}$ & $2.5 \mathrm{~V}$ & $12 \mathrm{~V}$ \\
\hline $\begin{array}{l}\text { Switching } \\
\text { frequency }\end{array}$ & $1.5 \mathrm{MHz}$ & $0.9 / 1.2 / 1.8 \mathrm{MHz}$ & $300 \mathrm{kHz}$ & $300-700 \mathrm{kHz}$ & $667 \mathrm{kHz}$ & $1.4 \mathrm{MHz}$ \\
\hline Output capacitor & $4.7 \mu \mathrm{F}$ & $4.7 \mu \mathrm{F}$ & $200 \mu \mathrm{F}$ & NA & $4.7 \mu \mathrm{F}$ & $6.8 \mu \mathrm{F}$ \\
\hline $\begin{array}{c}\text { Load transient } \\
\text { response } \\
\text { (light to } \\
\text { heavy)/(heavy to } \\
\text { light) }\end{array}$ & $\begin{array}{c}20 \mu \mathrm{s} / \mathrm{NA} \\
@ \triangle I_{o}=80 \mathrm{~mA}\end{array}$ & $\begin{array}{c}25 / 50 \mu \mathrm{s} \\
\left(a, \triangle I_{o}=120 \mathrm{~mA}\right.\end{array}$ & $\begin{array}{c}150 / 200 \mu \mathrm{s} \\
(a) \triangle I_{o}=10 \mathrm{~A}\end{array}$ & $\begin{array}{c}50 / 50 \mu \mathrm{s} \\
@ \triangle I_{o}=100 \mathrm{~mA}\end{array}$ & $\begin{array}{c}10 / 7 \mu \mathrm{s} \\
@ \triangle I_{o}=100 \mathrm{~mA}\end{array}$ & $\begin{array}{c}7 / 16 \mu \mathrm{s} \\
@ \triangle I_{o}=200 \mathrm{~mA}\end{array}$ \\
\hline $\begin{array}{c}\text { Output voltage } \\
\text { drop/loading } \\
\text { variation }\end{array}$ & $30 \mathrm{mV} / 80 \mathrm{~mA}$ & $2 \mathrm{~V} / 120 \mathrm{~mA}$ & $200 \mathrm{mV} / 10 \mathrm{~A}$ & $38 \mathrm{mV} / 100 \mathrm{~mA}$ & $50 \mathrm{mV} / 100 \mathrm{~mA}$ & $70 \mathrm{mV} / 200 \mathrm{~mA}$ \\
\hline Load regulation & $\begin{array}{c}0.5 \mathrm{mV} / \mathrm{mA} \\
@ V_{\text {in }}=12 \mathrm{~V}, \\
V_{\text {out }}=21 \mathrm{~V}\end{array}$ & $\begin{array}{c}11 \mathrm{mV} / \mathrm{mA} \\
\text { (a) } V_{\text {in }}=3.6 \mathrm{~V}, \\
V_{\text {out }}=25 \mathrm{~V}\end{array}$ & $\begin{array}{l}0.02 \mathrm{mV} / \mathrm{mA} \\
@ V_{\text {in }}=5 \mathrm{~V} \\
V_{\text {out }}=1.5 \mathrm{~V}\end{array}$ & $\begin{array}{c}0.38 \mathrm{mV} / \mathrm{mA} \\
\left(V_{\text {out }}=3.3 \mathrm{~V}\right.\end{array}$ & $\begin{array}{l}0.046 \mathrm{mV} / \mathrm{mA} \\
\text { @ } V_{\text {in }}=0.9 \mathrm{~V}\end{array}$ & $\begin{array}{l}0.1 \mathrm{mV} / \mathrm{mA} \\
@ V_{\text {in }}=3 \mathrm{~V}, \\
V_{\text {out }}=12 \mathrm{~V}\end{array}$ \\
\hline $\begin{array}{c}\text { Chip area with } \\
\text { pads }\end{array}$ & $6.178 \mathrm{~mm}^{2}$ & $0.34 \mathrm{~mm}^{2}$ & NA & $2.09 \mathrm{~mm}^{2}$ & $3 \mathrm{~mm}^{2}$ & $2.16 \mathrm{~mm}^{2}$ \\
\hline
\end{tabular}

*Reference [25] is a buck converter.

TABLE II

SUMMARY OF MEASUREMENT RESULTS

\begin{tabular}{|c|c|c|}
\hline \multicolumn{2}{|l|}{ Process } & TSMC 0.25 um 1P4M \\
\hline \multicolumn{2}{|l|}{ Input voltage } & $2.7-4.3 \mathrm{~V}$ \\
\hline \multicolumn{2}{|l|}{ Inductor/output capacitor } & $6.8 \mu \mathrm{H} / 6.8 \mu \mathrm{F}$ \\
\hline \multicolumn{2}{|l|}{ Switching frequency } & $1.4 \mathrm{MHz}$ \\
\hline \multicolumn{2}{|l|}{ Chip size } & $2.16 \mathrm{~mm}^{2}$ \\
\hline \multicolumn{2}{|l|}{ Output } & $12 \mathrm{~V}$ \\
\hline \multirow{4}{*}{ Proposed SDC technique } & \multirow{2}{*}{$\begin{array}{l}\text { Recovery time ( } 50 \mathrm{~mA}->250 \\
\mathrm{~mA}) \\
\text { Undershoot voltage } V_{\text {undershoot }}\end{array}$} & $7 \mu \mathrm{S}(\mathbf{1 0} \times$ fast $)$ \\
\hline & & $70 \mathrm{mV}(0.7 \times)$ \\
\hline & \multirow{2}{*}{$\begin{array}{l}\text { Recovery time (250 mA->50 } \\
\mathrm{mA}) \\
\text { Overshoot voltage } V_{\text {overshoot }}\end{array}$} & $16 \mu \mathrm{S}(5 \times$ fast $)$ \\
\hline & & $50 \mathrm{mV}(0.56 \times)$ \\
\hline \multirow{4}{*}{ Conventional method } & \multirow{2}{*}{$\begin{array}{l}\text { Recovery time ( } 50 \mathrm{~mA}->250 \\
\mathrm{~mA}) \\
\text { Undershoot voltage } V_{\text {undershoot }}\end{array}$} & $70 \mu \mathrm{S}$ \\
\hline & & $100 \mathrm{mV}$ \\
\hline & \multirow{2}{*}{$\begin{array}{l}\text { Recovery time ( } 250 \mathrm{~mA}->50 \\
\mathrm{~mA}) \\
\text { Overshoot voltage } V_{\text {overshoot }}\end{array}$} & $80 \mu \mathrm{S}$ \\
\hline & & $90 \mathrm{mV}$ \\
\hline
\end{tabular}

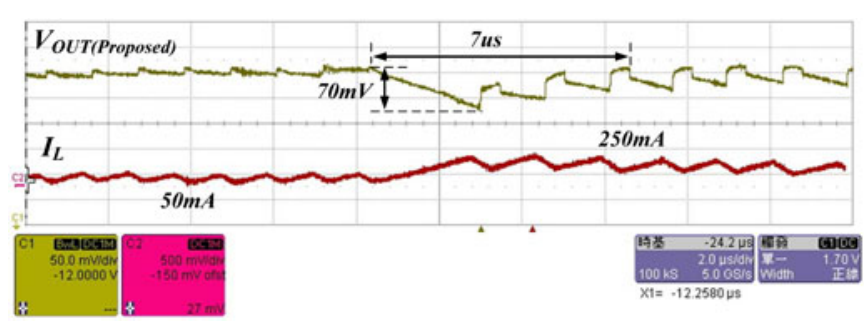

Fig. 11. Enlarged load transient waveforms can demonstrate the correct operation of the proposed technique.

respectively.The SDC controller can effectively reduce the transient dip voltage because of the constant duty ratio. Furthermore, the transient response time decreases from 70 to $7 \mu$ s when load current changes from 50 to $250 \mathrm{~mA}$. Conversely, the recovery time decreases from 80 to $16 \mu$ s when load current changes from 250 to $50 \mathrm{~mA}$. Table I shows that the SDC and VTE methods are more efficient than the previous approaches presented in [10], [24], and [25]-[27]. Fig. 11 enlarges the transient waveforms to demonstrate the correct operation of the proposed SDC controller. Table II shows the summary of the proposed SDC technique.

\section{CONCLUSION}

In this paper, we proposed a solid-duty ratio-control technique for application in the boost converter that maintains the duty ratio at a constant level to reduce dip voltage during the load transient period. Fast transient response can also be achieved because of the VTE controller. For edge-lit LED backlight systems, stable and regulated output driving can be provided by the proposed SDC technique. Experimental results show that compared with the conventional design without a fast transient 
technique, the proposed technique yields an enhancement of $30 \%$ and $80 \%$ for the undershoot voltage and recovery time, respectively.

\section{ACKNOWLEDGMENT}

The authors would like to thank Richtek Technology Corporation and Chunghwa Picture Tubes, Ltd. for their help.

\section{REFERENCES}

[1] C.-C. Chen, C.-Y. Wu, and T.-F. Wu, "LED back-light driving system for LCD panels," in Proc. IEEE Appl. Power Electron. Conf., 2006, pp. 381385

[2] H.-J. Chiu and S.-J. Cheng, "LED backlight driving system for large-scale LCD panels," IEEE Trans. Ind. Electron., vol. 54, no. 5, pp. 2751-2760, Oct. 2007.

[3] I.-H. Oh, "A single-stage power converter for a large screen LCD backlighting," in Proc.IEEE Appl. Power Electron. Conf., Mar. 2006, pp. 1058 1063.

[4] Y.-F. Chen, C.-C. Chen, and K.-H. Chen, "Mixed color sequential technique for reducing color breakup and motion blur effects," IEEE/OSA J. Display Technol., vol. 3, no. 4, pp. 377-385, Dec. 2007.

[5] T. Shirai, S. Shimizukawa, T. Shiga, S. Mikoshiba, and K. Kalantar, "RGBLED backlights for LCD-TVs with OD, 1D, and 2D adaptive dimming," in Soc. Inform. Display Dig. 44.4, 2006, pp. 1520-1523.

[6] O. Ronat, P. Green, and S. Ragona, "Accurate current control to drive high power LED strings," in Proc. IEEE Appl. Power Electron. Conf., 2006, pp. 376-380.

[7] M. Doshi and R. Zane, "Digital architecture for driving large LED arrays with dynamic bus voltage regulation and phase shifted PWM," in Proc. IEEE Appl. Power Electron. Conf., 2007, pp. 287-393.

[8] C.-Y. Hsieh, C.-Y. Yang, and K.-H. Chen, "A charge-recycling buck-store and boost-restore (BSBR) technique with dual outputs for RGB LED backlight and flashlight module," IEEE Trans. Power Electron., vol. 24, no. 8, pp. 1914-1925, Aug. 2009.

[9] Y. Chen, C. Chen, and K.-H. Chen, "Mixed color sequential technique for reducing color breakup and motion blur effects," IEEE J. Display Technol., vol. 3, no. 4, pp. 377-385, Dec. 2007.

[10] C.-Y Hsieh and K.-H Chen, "Boost DC-DC converter with fast reference tracking (FRT) and charge-recycling (CR) techniques for high-efficiency and low-cost LED driver," IEEE J. Solid-State Circuits, vol. 44, no. 9, pp. 2568-2580, Sep. 2009.

[11] W.-C. Wu, R. M. Bass, and J. R. Yeargan, "Eliminating the effects of the right-half plane zero in fixed frequency boost converters," in Proc. IEEE Power Electron. Spec. Conf., May 1998, pp. 362-366.

[12] D. Diaz, O. Garcia, J. A. Oliver, P. Alou, and J. A. Cobos, "Analysis and design considerations for the right half -plane zero cancellation on a boost derived dc/dc converter," in Proc. IEEE Power Electron. Spec. Conf., Jun. 2008, pp. 3825-3828.

[13] D. Ge and Z. Chen, "On-chip boost DC-DC converter in color OLED driver \& controller ICs for mobile application," in Proc. IEEE Int. Conf. ASIC, Oct. 2005, vol. 1, pp. 459-463.

[14] B. Bryant and M. K. Kazimierczuk, "Small-signal duty cycle to inductor current transfer function for boost PWM DC-DC converter in continuous conduction mode," in Proc. IEEE Int. Symp. Circuits Syst., May 23-26, 2004, vol. 5, pp. 856-859.

[15] R. D. Middlebrook, "Modeling current-programmed buck and boost regulators," IEEE Trans. Power Electron., vol. 4, no. 1, pp. 36-52, Jan. 1989.

[16] R. B. Ridley, "A new, continuous-time model for current-mode control," IEEE Trans. Power Electron., vol. 6, no. 2, pp. 271-280, Apr. 1991.

[17] T. Y. Man, P. K. T. Mok, and M. Chan, "A 0.9-V input discontinuousconduction- mode boost converter with CMOS -control rectifier," IEEE J. Solid-State Circuits, vol. 43, no. 9, pp. 2036-2046, Sep. 2008.

[18] T. Y. Man, P. K. T. Mok, and M. Chan, "A CMOS-control rectifier for discontinuous conduction mode switching dc-dc converters," in Proc. IEEE Int. Solid-State Circuits Conf., 2006, pp. 1408-1417.

[19] R. W. Erickson and D. Maksimovic, Fundamentals of Power Electronics, 2nd ed. Norwell, MA: Academic, 2001.

[20] C.-Y. Hsieh and K.-H. Chen, "Adaptive pole-zero position (APZP) technique of regulated power supply for improving SNR," IEEE Trans. Power Electron., vol. 23, no. 6, pp. 2949-2963, Nov. 2008.
21] C.-J. Chang and K.-H. Chen, "Bidirectional current-mode capacitor multiplier in DC-DC converter compensation," in Proc. Int. Workshop Syst.on-Chip, Jul. 2005, pp. 111-116.

[22] H.-H. Huang, C.-L. Chen, and K.-H. Chen, "Adaptive window control (AWC) technique for hysteresis DC-DC buck converters with improved light and heavy load performance," IEEE Trans. Power Electron., vol. 24 no. 6, pp. 1607-1617, Jun. 2009.

[23] C.-H. Liu, Y.-C. Hsieh, T.-J. Tai, and K.-H. Chen, "SAR-controlled adaptive (SARCA) off-time control without sensing resistor for achieving $94 \%$ efficiency and $98 \%$ accuracy," IEEE Trans. Circuits Syst. I, vol. 57, no. 6, pp. 1384-1394, Jun. 2010.

[24] W. Hollinger and M. Punzenberger, "An asynchronous 1.8 MHz DC/DC boost converter implemented in the current domain for cellular phone lighting management," in Proc. IEEE Eur. Solid-State Circuits Conf., Sep. 2006, pp. 528-531.

[25] O. Abdel-Rahman and I. Batarseh, "Transient response improvement in dc-dc converters using output current for faster transient detection," in Proc. IEEE Power Electron. Spec. Conf., 2007, pp. 157-160.

[26] K. Jung;J. Lim, J. Park, H. Yang, S. Cha, and J. Choi, "A high efficiency CMOS DC-DC boost converter with current sensing feedback," in Proc IEEE Int. Midwest Symp. Circuits Syst., 2005, vol. 2, pp. 1661-1664.

[27] T. Y. Man, P. K. T. Mok, and M. J. Chan, "A 0.9-V input discontinuousconduction-mode boost converter with CMOS-control rectifier," IEEE J. Solid-State Circuits, vol. 43, no. 9, pp. 2306-2346, Sep. 2008.

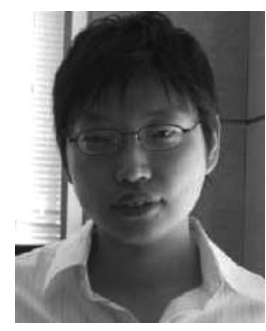

Han-Hsiang Huang received the B.S degree from the Department of Electrical Engineering, Chung Hua University, Hsinchu, Taiwan in 1997. He is currently working toward the M.S degree in the Department of Electrical and Control Engineering, National Chiao Tung University, Hsinchu, Taiwan.

$\mathrm{He}$ was an Application Engineer in Mitac, Hsinchu, Taiwan, from 1999 to 2001. From 2001 to 2006, he was a Device Engineer in VIS Co. Taiwan. His current research interests include power management IC design and analog IC design.

Chi-Lin Chen, photograph and biography not available at the time of publication.

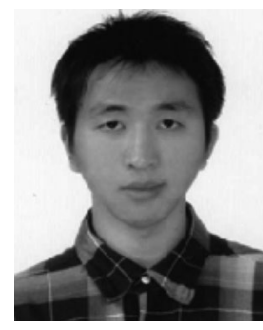

Dian-Rung Wu received the B.S. degree from the Department of Electrical Engineering, Chang Gung University, Taoyuan, Taiwan, in 2008, and the M.S. degree from the Department of Electrical and Control Engineering, National Chiao Tung University, Hsinchu, Taiwan, in 2010.

His research interests include power management IC designs and analog integrated circuits for portable devices.

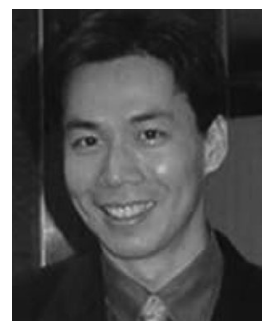

Ke-Horng Chen (M'04-SM'09) received the B.S., M.S., and Ph.D. degrees in electrical engineering from National Taiwan University, Taipei, Taiwan, in 1994, 1996, and 2003, respectively.

From 1996 to 1998, he was a part-time IC Designer at Philips, Taipei, Taiwan. From 1998 to 2000, he was an Application Engineer at Avanti, Ltd., Taiwan. From 2000 to 2003, he was a Project Manager at ACARD, Ltd., where he was engaged in designing power management ICs. He is currently an Associate Professor in the Department of Electrical Engineering, National Chiao Tung University, Hsinchu, Taiwan, where he organized a Mixed-Signal and Power Management IC Laboratory. He is the author or coauthor of more than 100 papers published in journals and conferences, and also holds several patents. His current research interests include power management ICs, mixed-signal circuit designs, display algorithm and driver designs of liquid crystal display TV, red, green, and blue color sequential backlight designs for optically compensated bend panels, and low-voltage circuit designs. 